Check for updates

Cite this: Chem. Commun., 2017, 53, 13253

Received 18th October 2017, Accepted 21st November 2017

DOI: $10.1039 / c 7 c c 08053 k$

rsc.li/chemcomm

\section{5-(Hydroxymethyl)uracil and -cytosine as potential epigenetic marks enhancing or inhibiting transcription with bacterial RNA polymerase $\dagger$}

\author{
Martina Janoušková, $\ddagger^{\mathrm{a}}$ Zuzana Vaníková, $\ddagger^{\mathrm{b}}$ Fabrizia Nici, ${ }^{\mathrm{b}}$ Soňa Boháčová, ${ }^{\mathrm{b}}$ \\ Dragana Vítovská, ${ }^{a}$ Hana Šanderová, ${ }^{a}$ Michal Hocek (D) *bc and Libor Krásný (D) *a
}

DNA templates containing 5-hydroxymethyluracil or 5-hydroxymethylcytosine were used in an in vitro transcription assay with RNA polymerase from Escherichia coli. A strong enhancement of transcription was observed from DNA containing the Pveg promoter whereas a decrease was observed from DNA containing the rrnB P1 promoter, suggesting that they may act as epigenetic marks.

Modifications of DNA by epigenetic bases (i.e. 5-methylcytosine, $5 \mathrm{mC}$ ) play critical roles in the regulation of gene expression both in eukaryotes and prokaryotes and their dysregulation may lead to diseases. ${ }^{1}$ Recent advances in detection techniques have resulted in the discovery of the new bases 5 -hydroxymethylcytosine (5hmC), 5-formylcytosine (5fC) and 5-carboxycytosine $(5 \mathrm{caC}) .^{2,3}$ More recently, also 5-hydroxymethyluracil (5hmU), previously detected in bacteriophages, ${ }^{4,5}$ dinoflagellates $^{6}$ and leishmania, ${ }^{7}$ has been found in eukaryotic genomes ${ }^{8}$ where its level appears to be cell type-specific. ${ }^{9}$ The level of 5-hydroxymethyl-2'-deoxyuridine in blood DNA was investigated as a marker for breast cancer. ${ }^{10}$ It is being hotly debated whether these modifications function as regulators of gene expression or whether they are just intermediates in active demethylation of DNA or products of oxidative damage. While the role of $5 \mathrm{hmC}$ in regulation of transcription has been demonstrated, ${ }^{11}$ the role of $5 \mathrm{hmU}$ remains unclear. $^{12}$ The $5 \mathrm{hmU}$ base can be generated by oxidation/hydroxylation of thymine by the Ten-Eleven-Translocation (TET) proteins ${ }^{13}$ or result from deamination of $5 \mathrm{hmC} .{ }^{14}$ The DNA containing $5 \mathrm{hmU}$

\footnotetext{
${ }^{a}$ Dept. of Molecular Genetics of Bacteria, Institute of Microbiology of the Czech Academy of Sciences, CZ-14220 Prague 4, Czech Republic.

E-mail: krasny@biomed.cas.cz

${ }^{b}$ Institute of Organic Chemistry and Biochemistry of the Czech Academy of Sciences, Flemingovo nam. 2, 16610 Prague 6, Czech Republic. E-mail: hocek@uochb.cas.cz 'Dept. of Organic Chemistry, Faculty of Science, Charles University in Prague, Hlavova 8, CZ-12843 Prague 2, Czech Republic

$\dagger$ Electronic supplementary information (ESI) available: Extended results and discussion, experimental part, sequencing of all modified DNA templates. See DOI: $10.1039 / \mathrm{c} 7 \mathrm{cc} 08053 \mathrm{k}$

\# These authors contributed equally.
}

was reported to be more flexible and hydrophilic. ${ }^{15}$ The Schultz lab has evolved ${ }^{16}$ a bacterium which replaced $\mathrm{T}$ with $5 \mathrm{hmU}$ in the genome showing that this base in principle is compatible with replication and transcription, as has been also previously reported by Herala and Vilpo from biochemical experiments. ${ }^{17}$

In order to shed light on the possible regulatory role of $5 \mathrm{hmU}$, we performed an in vitro transcription study on modified DNA templates (containing $5 \mathrm{hmU}, 5 \mathrm{hmC}, 5 \mathrm{mC}$ or U) with Escherichia coli RNA polymerase (RNAP). The assay was previously developed for the systematic study of the effects of non-natural DNA modifications in the major groove on prokaryotic transcription. ${ }^{18}$ Here we used four templates with different promoters (Fig. 1) but the same transcribed region. The first two promoters were Pveg and rrnB P1, respectively, both from Bacillus subtilis and both well-recognized by the $E$. coli RNAP holoenzyme containing the primary sigma factor, $\sigma^{70} \cdot{ }^{19}$ The other two promoters were reciprocal chimeras made from the two former promoters to identify regions within the promoters where the modifications affected transcription the most.

We started by studying transcription on the four fully modified DNA templates, where all $\mathrm{T}$ or $\mathrm{C}$ bases were replaced with the epigenetic bases (Fig. 1). The templates were prepared by PCR using d5hmUTP ${ }^{20}$ or commercial d5hmCTP, ${ }^{21} \mathrm{~d} 5 \mathrm{mCTP}$ or dUTP (see Fig. S1-S4 in the ESI $\dagger$ ). An initial challenge was how to quantify the relative concentrations of the modified DNA templates since the modified bases may influence the extinction coefficient (NanoDrop) or the intercalation or fluorescence of DNA dyes (DNA gel staining). Since the use of $5^{\prime}$-FAM-labeled primers ${ }^{18}$ and fluorescence quantification of PCR products gave results of limited reproducibility, we prepared radioactively labelled DNA templates (using ${ }^{32} \mathrm{P}$-labelled primers for PCR) and found that the concentrations measured by radioactivity did not correlate with those measured on the NanoDrop but they correlated reasonably well $( \pm 10-15 \%)$ with the relative DNA amounts obtained from the fluorescence intensity of the DNA spots on gels stained by GelRed. These two methods were then used for determination of the relative concentrations of the DNA templates.

The first in vitro transcription experiments with the fully modified templates with the Pveg promoter surprisingly showed 
A
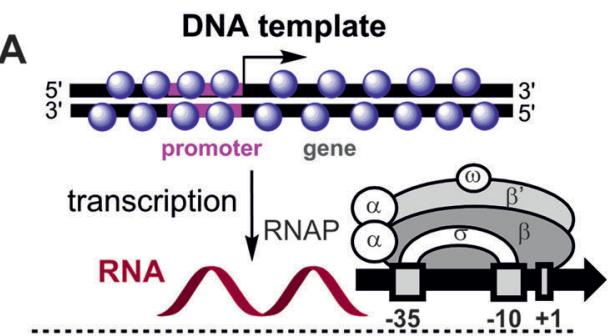

Epigenetic bases $Q=$

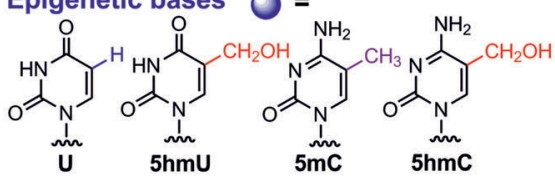

B

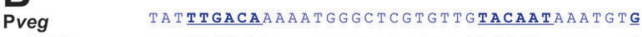

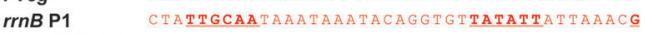

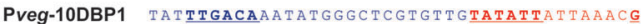
rrnB P1-10Dveg TITTGCAATAAATAAATACAGGTGTTACAATAAATGTG
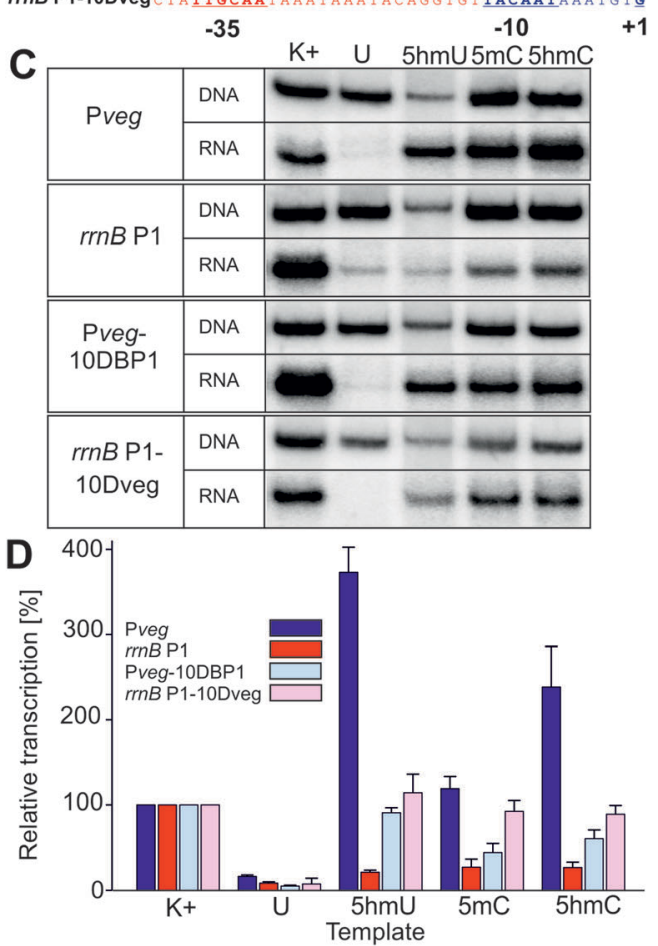

Fig. 1 (A) Scheme of the in vitro transcription experiment using a fully base-modified DNA template and structures of the epigenetic bases. (B) Promoters and hybrid sequences used. (C) Gel electrophoresis of the ${ }^{32} \mathrm{P}$-labelled fully-modified DNA templates and the corresponding RNA transcripts. (D) Quantitation of transcriptions from fully-modified templates containing different modifications. $K+$ is the natural (non-modified) DNA template. The graph (also in Fig. 2) shows quantitation from at least three independent experiments. $K+$ was set to be $100 \%$. The error bars are $\pm S D$.

that the presence of $5 \mathrm{hmU}$ or $5 \mathrm{hmC}$ enhanced transcription by a factor of 3.5 or 2.3 , respectively, whereas the template containing $5 \mathrm{mC}$ was transcribed with similar efficiency as the natural DNA (Fig. 1). On the other hand, and in accordance with our previous observations, ${ }^{18}$ the presence of $\mathrm{U}$ in the template significantly decreased transcription. It should be noted that in these experiments, the level of the $5 \mathrm{hmU}$ template was usually lower than the levels of the other templates due to technical problems with the 5hmU-DNA template preparation (lower efficiency of the PCR using d5hmUTP). To exclude the possibility that normalization to the relatively low level of the 5hmU DNA could have overrated the apparent stimulation, we performed transcription experiments with $\mathrm{U}$ and 5hmU DNA where we used equal amounts of DNA templates based on their prior quantitation from DNA gels. The results of this experiment (Fig. S35, ESI $\dagger$ ) were in accordance with the observation in Fig. 1 confirming the significant enhancement of transcription with hmU-modified DNA. When using modified DNA templates containing the $r r n \mathrm{~B}$ P1 promoter, the presence of any modified base decreased transcription significantly. With model hybrid sequences containing part of Pveg and part of $r r n \mathrm{~B} \mathrm{P} 1$, we observed transcription at about the same or just slightly decreased level compared to natural DNA templates for $5 \mathrm{hmU}, 5 \mathrm{hmC}$ and $5 \mathrm{mC}$, implying that both parts of the promoter might be required for the observed effects (Fig. 1).

In order to identify which parts of the template are responsible for the unexpected enhancement of transcription, we prepared and systematically tested a series of partially modified templates containing the Pveg promoter (Fig. 2). For the schemes of synthesis of the partially modified templates by a combination of PCR, primer extension and ligations, see the ESI, $\dagger$ Fig. S5-S9. Templates modified in the gene region (with unmodified promoter) showed slightly decreased transcription but the effect was not very strong and appeared to be nonspecific (A). On the other hand, templates modified in both strands of the promoter region displayed similar trends as the fully modified templates (significant enhancement of transcription for $5 \mathrm{hmU}$ and moderate enhancement for $5 \mathrm{hmC}$ templates, B). Transcription of templates modified in the template strand of the promoter showed an increase for $\mathrm{U}$, a slight enhancement for $5 \mathrm{hmU}$, and an even more pronounced enhancement for $5 \mathrm{hmC}$ (C). Transcription of the template modified in the non-template strand of the promoter (D) showed strong inhibition for $\mathrm{U}$ as previously predicted, ${ }^{18}$ a significant enhancement for $5 \mathrm{hmU}$ and a less significant enhancement for $5 \mathrm{hmC}$. This clearly demonstrates that in the case of $5 \mathrm{hmU}$ it is the non-template strand of the promoter that is critically important for the regulation of transcription by this epigenetic mark. Further detailed structural and functional studies will be needed to understand the mechanism of the transcription enhancement and inhibition.

To conclude, we have shown here that both $5 \mathrm{hmC}$ and 5 hmU affect transcription by bacterial RNAP depending on the promoter sequence. For the first time, we directly observed strong enhancement of transcription of templates containing $5 \mathrm{hmU}$ or $5 \mathrm{hmC}$ in an in vitro enzymatic assay. In the case of $5 \mathrm{hmU}$, both the enhancement and inhibition are mediated predominantly by interactions of the promoter nontemplate strand with RNAP. We note that while we used for our studies a well-characterized promoter (Pveg), other promoters may exist in the genome where random modifications of even single bases may have even more pronounced effects on transcription. Taken together, this illustrates the strong potential of $5 \mathrm{hmU}$ to alter gene expression. Therefore, we speculate that the presence of $5 \mathrm{hmU}$ in regulatory DNA sequences in the bacterial cell may 
A
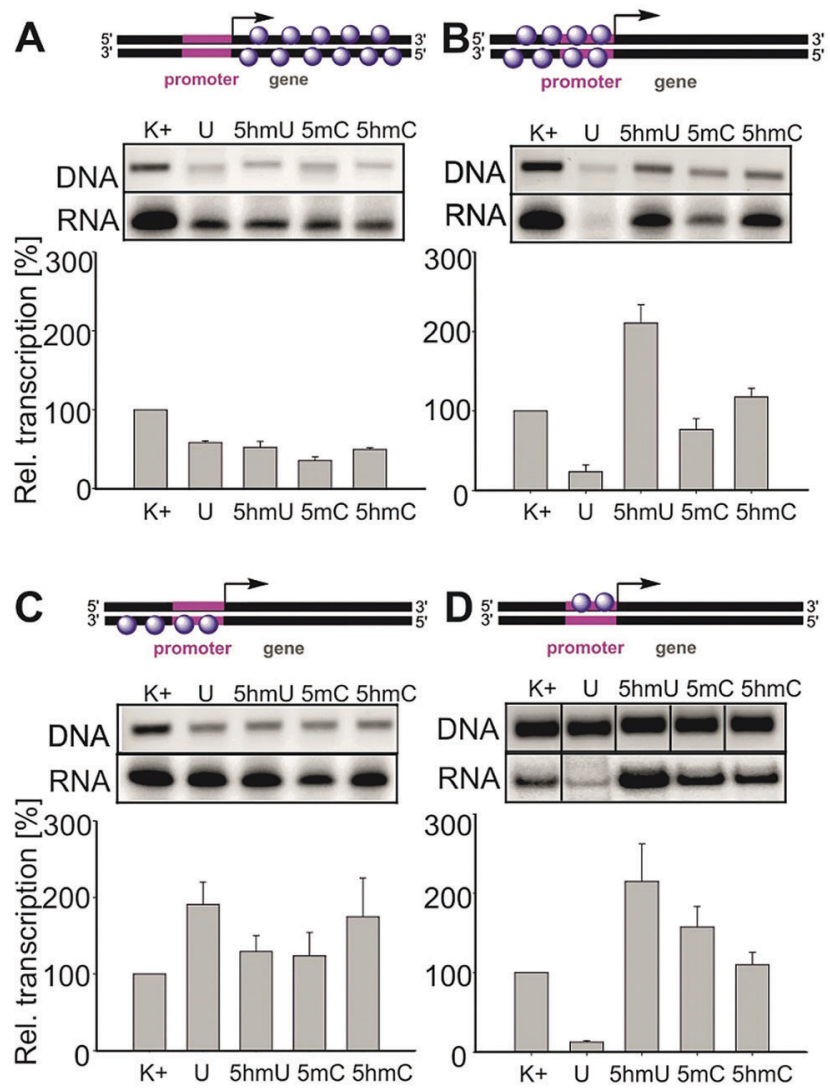

Fig. 2 Gel electrophoreses of DNA templates (GelRed-stained) and RNA transcripts (radioactively labelled) and relative transcription of partially modified DNA templates. (A) Templates modified in both strands of the gene region. (B) Templates modified in both strands of the promoter region. (C) Templates modified in the template strand of the promoter region. (D) Templates modified in the non-template strand of the promoter region.

contribute to diversification of the population, enhancing its chances of survival. As $5 \mathrm{hmU}$ occurs in bacteriophage DNA ${ }^{4,5}$ where it was described to facilitate binding of some transcription factors, ${ }^{22}$ it also may give it an advantage in transcription over the bacterial DNA. Notwithstanding these speculations, artificial modification of DNA templates by $5 \mathrm{hmU}$ may in principle serve for chemical regulation of transcription (chemical epigenetics) or even for the development of chemical switches. ${ }^{20,23}$ Studies along these lines, as well as investigation of the effects of these epigenetic bases on eukaryotic transcription, are under way.

This work was supported by the Czech Academy of Sciences (Praemium Academiae award to M. H.), and by the Czech Science Foundation (17-03419S to M. J., Z. V., S. B., L. K. and M. H.). Part of the project was supported by the C4Sys infrastructure.

\section{Conflicts of interest}

There are no conflicts to declare.

\section{Notes and references}

1 (a) K. Chen, B. S. Zhao and C. He, Cell Chem. Biol., 2016, 23, 74-85; (b) J. H. Gommers-Ampt and P. Borst, FASEB J., 1995, 9, 1034-1042; (c) E. A. Raiber, R. Hardisty, P. van Delft and S. Balasubramanian, Nat. Rev. Chem., 2017, 1, 0069.

2 X. Lu, B. S. Zhao and C. He, Chem. Rev., 2015, 115, 2225-2239.

3 (a) M. Wagner, J. Steinbacher, T. F. J. Kraus, S. Michalakis, B. Hackner, T. Pfaffeneder, A. Perera, M. Müller, A. Giese, H. A. Kretzschmar and T. Carell, Angew. Chem., Int. Ed., 2015, 54, 12511-12514; (b) T. Pfaffeneder, B. Hackner, M. Truss, M. Münzel, M. Müller, C. A. Deiml, C. Hagemeier and T. Carell, Angew. Chem., Int. Ed., 2011, 50, 7008-7012; (c) D. Globisch, M. Münzel, M. Müller, S. Michalakis, M. Wagner, S. Koch, T. Brückl, M. Biel and T. Carell, PLoS One, 2010, 5, e15367.

4 H. Witmer, J. Virol., 1981, 39, 536-547.

5 R. G. Kallen, M. Simon and J. Marmur, J. Mol. Biol., 1962, 5, 248-250.

6 P. M. M. Rae, Science, 1976, 194, 1062-1064.

7 F. Kawasaki, D. Beraldi, R. E. Hardisty, G. R. McInroy, P. van Delft and S. Balasubramanian, Genome Biol., 2017, 18, 23.

8 T. Pfaffeneder, F. Spada, M. Wagner, C. Brandmayr, S. K. Laube, D. Eisen, M. Truss, J. Steinbacher, B. Hackner, O. Kotljarova, D. Schuermann, S. Michalakis, O. Kosmatchev, S. Schiesser, B. Steigenberger, N. Raddaoui, G. Kashiwazaki, U. Müller, C. G. Spruijt, M. Vermeulen, H. Leonhardt, P. Schär, M. Müller and T. Carell, Nat. Chem. Biol., 2014, 10, 574-581.

9 J. Guz, D. Gackowski, M. Foksinski, R. Rozalski and R. Olinski, Biol. Reprod., 2014, 91, 55.

10 Z. Djuric, L. K. Heilbrun, M. S. Simon, D. Smith, D. A. Luongo, P. M. LoRusso and S. Martino, Cancer, 2006, 77, 691-696.

11 (a) A. Perera, D. Eisen, M. Wagner, S. K. Laube, A. F. Künzel, S. Koch, J. Steinbacher, E. Schulze, V. Splith, N. Mittermeier, M. Muller, M. Biel, T. Carell and S. Michalakis, Cell Rep., 2015, 11, 283-294; (b) C. M. Greco, P. Kunderfranco, M. Rubino, V. Larcher, P. Carullo, A. Anselmo, K. Kurz, T. Carell, A. Angius, M. V. G. Latronico, R. Papait and G. Condorelli, Nat. Commun., 2016, 7, 12418; (c) C. You, D. Li, X. Dai and Y. Wang, Sci. Rep., 2014, 4, 7052; (d) L. Wang, Y. Zhou, L. Xu, R. Xiao, X. Lu, L. Cheng, J. Chong, H. Li, C. He, X.-D. Fu and D. Wang, Nature, 2015, 523, 621-625; (e) M. W. Kellinger, C.-X. Song, J. Chong, X.-Y. Lu, C. He and D. Wang, Nat. Struct. Mol. Biol., 2012, 19, 831-833.

12 R. Olinski, M. Starczak and D. Gackowski, Mutat. Res., 2016, 767, 59-66.

13 M. Yu, C.-X. Song and C. He, Methods, 2015, 72, 16-20.

14 S. Carson, J. Wilson, A. Aksimentiev, P. R. Weigele and M. Wanunu, Nucleic Acids Res., 2016, 44, 2085-2092.

15 F. Kawasaki, P. Murat, Z. Li, T. Santner and S. Balasubramanian, Chem. Commun., 2017, 53, 1389-1392.

16 A. P. Mehta, H. Li, S. A. Reed, L. Supekova, T. Javahishvili and P. G. Schultz, J. Am. Chem. Soc., 2016, 138, 7272-7275.

17 A. M. Herala and J. A. Vilpo, Biochemistry, 1981, 28, 8274-8277.

18 V. Raindlová, M. Janoušková, M. Slavičková, P. Perlíková, S. Boháčová, N. Milisavljevič, H. Šanderová, M. Benda, I. Barvík, L. Krásný and M. Hocek, Nucleic Acids Res., 2016, 44, 3000-3012.

19 L. Sojka, T. Kouba, I. Barvík, H. Šanderová, Z. Maderová, J. Jonák and L. Krásný, Nucleic Acids Res., 2011, 39, 4598-4611.

20 Z. Vaníková and M. Hocek, Angew. Chem., Int. Ed., 2014, 53, 6734-6737.

21 B. Steigenberger, S. Schiesser, B. Hackner, C. Brandmayr, S. K. Laube, J. Steinbacher, T. Pfaffeneder and T. Carell, Org. Lett., 2013, 15, 366-369.

22 J. R. Greene, L. M. Morrissey, L. M. Foster and E. P. Geiduschek, J. Biol. Chem., 1986, 27, 12820-12827.

23 P. Kielkowski, H. Macíčková-Cahová, R. Pohl and M. Hocek, Angew. Chem., Int. Ed., 2011, 50, 8727-8730. 